\title{
CORE GROUPS AND THE TRANSMISSION OF HIV: LEARNING FROM MALE SEX WORKERS
}

\author{
MELISSA PARKER
}

International Medical Anthropology Programme, Brunel University, UK

\begin{abstract}
Summary. A growing and substantial body of research suggests that female sex workers play a disproportionately large role in the transmission of HIV in many parts of the world, and they are often referred to as core groups by epidemiologists, mathematical modellers, clinicians and policymakers. Male sex workers, by contrast, have received little attention and it is not known whether it is helpful to conceptualize them as a core group. This paper draws upon ethnographic research documenting social and sexual networks in London and looks at the position of five male sex workers within a network comprising 193 men and seven women (as well as 1378 anonymous sexual contacts and 780 commercial contacts). In so doing, it suggests that there is no evidence to show that male sex workers are more or less likely to acquire or transmit HIV in the course of commercial sex compared with other types of sexual relationships. In addition, men engaging in non-commercial sex all reported having unprotected sex in a variety of contexts and relationships and there is no evidence to suggest that men who are not sex workers play less of a role in the transmission of HIV. In short, these data suggest that it would be inappropriate to conceptualize male sex workers as a core group. This is not to suggest that public policy should continue to overlook male sex workers. New and inventive approaches are required to reach out to a vulnerable but diverse group of men, selling sex for a variety of reasons; even if these men are no more vulnerable to acquiring and/or transmitting HIV than other men and women that form part of their network.
\end{abstract}

\section{Introduction}

Commercial sex workers are widely believed to play a central role in the transmission of HIV in parts of Africa (D'Costa et al., 1985; Moses et al., 1991; Steen et al., 2000; Boily et al., 2002); Asia (Hanenberg et al., 1994) and Europe (Aral et al., 2003); and they are often referred to as core groups by epidemiologists, mathematical modellers, clinicians and policymakers as a way of highlighting the disproportionately large role they can play in the transmission of HIV. Drawing upon epidemiological and clinical 
research, academics and policymakers have also suggested that interventions targeting commercial sex workers provide a cost-effective way of reducing the transmission of HIV and other sexually transmitted infections. Some of this work has been critiqued in recent years (see, for example, Fichtenberg \& Ellen, 2003; Parker, 2003). However, it would be fair to say that discussions about commercial sex workers and core groups have focused either explicitly or implicitly on female sex workers rather than male sex workers; and it is not at all clear what role, if any, male sex workers play in the transmission of HIV. This paper endeavours to reverse this trend. With reference to ethnographic research detailing sexual and social links between male sex workers, their clients and the wider community in London, UK, it also responds to a plea by Aral et al. (2002) 'to look at network connections around individual sex workers' (Aral et al., 2002, p. i7) with a view to addressing the following questions: how does an understanding of the beliefs and behaviours of male sex workers, acquired through the study of sexual networks, help us understand the transmission of HIV? Are there any indications to suggest that male sex workers play a central role in the transmission of HIV in London, UK? To what extent can insights emerging from ethnographic research enable us to critically reflect upon the assumptions embedded in epidemiological concepts such as core groups? How can these insights be harnessed to inform public policy, nationally and internationally?

The paper is divided into three parts to explore these questions. Part one explains how and why the concept of a core group has become so central to understanding the epidemiology of HIV and other sexually transmitted infections; and the assumptions embedded in the concept of a core group are highlighted. Part two presents a brief overview of research investigating sexual networks in London. There are five male sex workers in the network presented and a detailed case study about one of them is discussed in this section. Drawing upon information acquired from open-ended, unstructured interviews as well as participant observation fieldwork, the third, and final, part of the paper suggests that male sex workers are vulnerable to acquiring and/or transmitting infection, but this is just as likely to occur in the context of non-commercial relationships as commercial relationships. In view of the fact that all other informants who did not sell sex also reported having had unprotected anal sex, it thus becomes difficult, if not impossible, to say that male sex workers are more likely to transmit HIV than any other group in the network. It follows that it is not at all helpful to suggest that male sex workers constitute a 'core' group whilst other groups are 'peripheral' to the transmission of HIV.

But, first, what is meant by the term core group? The term core group was first used by the biomathematicians Yorke et al. (1978) to explain the transmission of gonorrhoea. With reference to clinical data collected from the USA, they suggested that the persistence of gonococcal infection could be explained by the fact that a small number of people, approximately $20 \%$, have large numbers of sexual contacts. These people could be defined according to a variety of social, demographic, geographic and behavioural characteristics that are stable over time, and they play a disproportionate role in the transmission of gonorrhoea. It is thus helpful to conceptualize them as a core group. Indeed, Yorke et al. (1978) and Hethcote \& Yorke (1984) developed a series of mathematical models to show that if gonorrhoea could be removed from the 
core then it would not be possible for the organism to remain endemic and the infection would eventually disappear.

May \& Anderson (1987) developed the ideas in the model and applied it to the study of HIV transmission. Drawing upon ideas current in the field of population ecology, they suggested that the transmission of HIV could be predicted by acquiring an understanding of the basic reproductive rate, symbolized as $R_{0}$. Three biological and behavioural determinants were singled out as playing a crucial role in facilitating the rate of transmission: the transmission efficiency of the organism $(\beta)$; the average number of sexual contacts per unit of time $(c)$; and the duration of infectiousness $(D)$. The formula, $\mathrm{R}_{0}=\beta \times c \times D$, captures the relationship between biological and behavioural determinants.

According to this line of reasoning, factors facilitating the spread of HIV include unprotected sex; sex with large numbers of people once infected; and prolonged infection due to the absence of symptoms or failure to obtain effective treatment. Subsequent papers by Anderson (1988, 1990a, 1990b) and May \& Anderson (1988) elaborated this mathematical model and detailed the range of biological and behavioural factors that influence transmission. These include variations in the rate of partner change within a population; the number of sex acts per partner; variation in the infectivity of individuals during periods of infectiousness; and mixing patterns between different subgroups of a population.

A number of biomedically orientated researchers have drawn upon insights emerging from these papers to suggest that sex workers constitute a core group and thus play a central role in the transmission of HIV. Kreiss et al. (1986), Plummer et al. (1991), Moses et al. (1991) and Boily et al. (2002), for example, have all suggested that female sex workers constitute a core group worthy of targeted health promotion campaigns. Their research is based upon clinical and quantitative socio-epidemiological data. It is premised upon the following: sex workers are a fairly homogenous group and easily identifiable as they have a clear social identity. In addition, they have a relatively large number of sexual contacts and they are, therefore, vulnerable to acquiring infection. In the event that they become infected, they are more likely to transmit their infection to others - at least compared with individuals with fewer contacts. It thus follows that it is both helpful and cost-effective to provide sex workers with information about HIV and AIDS as well as condoms as a change in their behaviour would necessarily reduce the prevalence and incidence of HIV and other sexually transmitted infections among sex workers and, therefore, their contacts, their contacts' contacts and so on.

Unfortunately, ethnographic research detailing the social, economic and sexual networks of sex workers and their contacts has not been undertaken. It is thus not clear whether the assumptions embedded in the research cited above are appropriate or not. However, there are reasons to be cautious. None of these researchers appear to have taken the time to talk to their study participants in an open-ended way. Rapport and trust are unlikely to have been forthcoming as questionnaire survey work in clinical and epidemiological settings, however well executed, inevitably precludes detailed discussion of issues and questions that may not, at first sight, appear to be relevant. Certainly, their publications do not convey a desire to question or reflect upon the extent to which epidemiological understandings of 'sexual 
contacts', 'sex', 'sex work', 'unsafe sex' etc. match those of their study participants. It is thus difficult to know how participants may have interpreted questions and whether their understandings of the questions matched that of the researchers. Moreover, their willingness to respond accurately to direct questions on sensitive issues, in the absence of a trusting relationship with an interviewer, is open to question.

Ethnographic research provides an opportunity to overcome the limits of working in structured and semi-structured ways in clinical and epidemiological settings. By establishing rapport and trust with informants, over a protracted period of time, it becomes possible to appreciate the social, political and economic context in which sex occurs; and to critically reflect upon the assumptions guiding epidemiological and social research. With respect to research on core groups and sex workers it thus becomes important to ask: 'does ethnographic research support the idea that sex workers are usefully conceptualized as a core group and play a central role in the transmission of HIV?' The opportunity to explore this question arose in the course of doing some research on sexual networks and HIV transmission in London, UK, between August 1994 and March 1996. A small amount of follow-up work also took place between June 1996 and September 1998.

This research entailed participant observation fieldwork in a wide range of settings (including a clinic for sexually transmitted diseases, the flats and houses of informants as well as a variety of bars, pubs, clubs and cafes); and a total of 57 open-ended, unstructured interviews were undertaken with one woman and nineteen men. These informants were all linked to each other through a variety of sexual links, and the way in which these links were identified has been discussed in detail in Parker et al. (1998). Briefly, two methods were used to identify sexual and social links: clinic referrals at a London teaching hospital and snowball sampling. With respect to the latter, informants who had been recruited through the clinic were asked to get in touch with current and past sexual contacts with a view to asking them whether they would be willing to participate in the study. Wherever possible, these people were then interviewed and they, in turn, were asked to get in touch with past and present sexual contacts as well as friends with a view to building up a detailed picture of the social and sexual links between people in London. This paper focuses on the position of male sex workers in this network. It presents a detailed case study about a male sex worker called 'Roberto' (a pseudonym); and analyses information emerging from the case study in the light of ethnographic data detailing social and sexual links between all 20 informants. Some of the details presented in the case study have been modified to preserve anonymity. The names of other sex workers mentioned in the text have also been altered.

\section{Male sex workers and HIV in London}

By way of background, the number of reported cases of HIV in the UK has increased over time. Recent data from the Health Protection Agency, for example, shows that the total number of people that had been reported with HIV increased from 27,434 in 1994 to 68,513 in December 2004. The majority of these cases are concentrated in London and occur among men who have sex with men, and these men remain the 
group most at risk of acquiring HIV within the UK (Health Protection Agency, 2005). However, there are no data monitoring changes in the prevalence and incidence of HIV among male sex workers. This betrays the fact that very little biomedical research has been undertaken with male sex workers in the UK. The small amount that has been done suggests that male sex workers have higher rates of HIV than female sex workers (McKeganey, 1994). In London, for example, Tomlinson et al. (1991) documented the fact that $27 \%$ of 57 male sex workers were HIV positive; and a cross-sectional study undertaken by Sethi et al. (2004) found that $10 \%$ of the 224 male sex workers tested were HIV positive. In addition, it is worth noting that four out of the five sex workers in the network presented in this paper are HIV positive. By contrast, Ward et al. (1999) found that $1 \cdot 7 \%$ of 302 female sex workers in London were HIV positive. This interesting piece of research has recently been cited as proof that '... although commercial sex workers in the UK are at increased risk of sexually transmitted diseases, including HIV, compared with the rest of the population there is no evidence that they have played a significant role in HIV spread within the UK ...' (CDSC, 2000, p. 24). However, it is not at all clear from this policy document whether the term 'commercial sex workers' is meant to include or exclude male sex workers. In the light of the biomedical data cited above, there is clearly a pressing need to make an explicit distinction between female and male sex workers, and to investigate whether the latter group are usefully conceptualized as a core group. It is also important to note that research exploring the social context in which sex occurs between men in London is limited (see, for example, Davies \& Feldman, 1999); and to date, the only research that has analysed the position of sex workers, male or female, in relation to their sexual and social networks is that undertaken by Parker et al. (1998) and Parker (1999). This research suggested that some male sex workers facilitate the transmission of HIV to heterosexual populations, but the papers did not reflect on this finding in the light of the epidemiological literature on core groups. The following case study helps to address this issue.

\section{Case study: Roberto}

Roberto is a 24 year old from Brazil, South America. He came to London shortly after completing two years of a university degree in biochemistry, and he currently shares a one-bedroom basement flat in West London with an ex-boyfriend from Brazil. He is HIV positive and seeking permanent residence from the Home Office. At our first meeting he said that he ran a small business and that he had had four anonymous sexual contacts in a park close to his flat over the last few months. During the fourth interview, he mentioned the fact that he had heard a friend and former sexual contact talking about me in a positive way and that he no longer thought I was a spy from the Home Office.

Not surprisingly, therefore, he felt much more able to speak freely about some of the things that were going on in his life. In particular, he spoke about the economic, social and sexual aspects of his life in London and these are discussed in turn. First, the economic basis of Roberto's life is precarious. He is unable to get salaried work as he is not entitled to be formally employed or to receive full state benefits while the Home Office considers his application for permanent residence. He does, however, 
receive a disability allowance of $£ 70$ a week. His rent is currently $£ 100$ a week and additional income to cover the rest of his rent, food and other living expenses is thus generated by selling precious stones such as emeralds (the source of which remains ambiguous). He also takes and sells photographs of young men. Unfortunately, the market for precious stones is unreliable and he has insufficient equipment to make much money from his photographic expertise. He thus covers the shortfall by selling sex and this is done in a variety of ways: working for an escort agency, advertising privately in the gay press and working in a 'whore house' in central London.

It would have been quite inappropriate to have asked my informant about the number and type of commercial sexual contacts in any systematic way as he found his situation distressing and disturbing. He did, however, talk candidly about the fact that he sometimes sold unprotected anal sex as it was so much more lucrative. At the 'whore house' in central London, for example, the manager would charge a flat rate of $£ 50$ and then give half of this to my informant. The possibility of earning an additional $£ 50-£ 100$ by selling unprotected anal sex to a visiting client often arose and, as far as Roberto was concerned, the sum of money involved was too high to refuse.

It is hardly surprising that Roberto accepted additional income for selling unprotected anal sex as debt was a recurring theme throughout our interviews. He often talked with concern and fear about how he was going to pay for a $£ 300$ telephone bill, a council tax bill of $£ 100$ and debts to friends totalling $£ 300$. His sister, a recent graduate from London University, had agreed to send him some money but he remained worried as he knew that this would not provide a permanent solution to his economic difficulties.

Roberto felt very ambivalent about selling sex. On the one hand, it was the 'easiest' and most 'obvious' way to resolve pressing economic difficulties and he clearly felt that 'once you start, its hard to stop ... you meet more interesting people, it's more challenging [as] you have to open your mind and go as far as you can go [and] ... the money is better [at least] ... compared to being a waiter, which is badly paid'.

But with tears pouring down his face, he went on to say: "If I infect a lot of people, it's not my fault. I tried to get help from a lot of people [lawyers, psychiatrists, doctors] ... I didn't get it ... what can I do? ... I can't help it if I infect others.'

Whatever the stated reasons for selling unprotected anal sex, it is also the case that Roberto did not only have unprotected anal sex with commercial contacts. He also had unprotected anal sex with his boyfriends, friends, casual contacts and one-off, more anonymous encounters. His position in the network is encircled by dotted lines and depicted in Figs 1 and 2. Figure 2 shows that over a 12-month period Roberto had at least four anonymous sexual contacts in a park in central London; as well as sex with two boyfriends, two friends, four casual contacts and three other male sex workers that he came to know whilst photographing them at a 'whore house' in London. Unprotected anal sex occurred in the context of all these different kinds of relationships and, according to Roberto, he only spoke about his HIV status to two of these contacts (one of whom was a sort of boyfriend who had an on-going relationship with another man and was probably HIV positive himself); and the other 


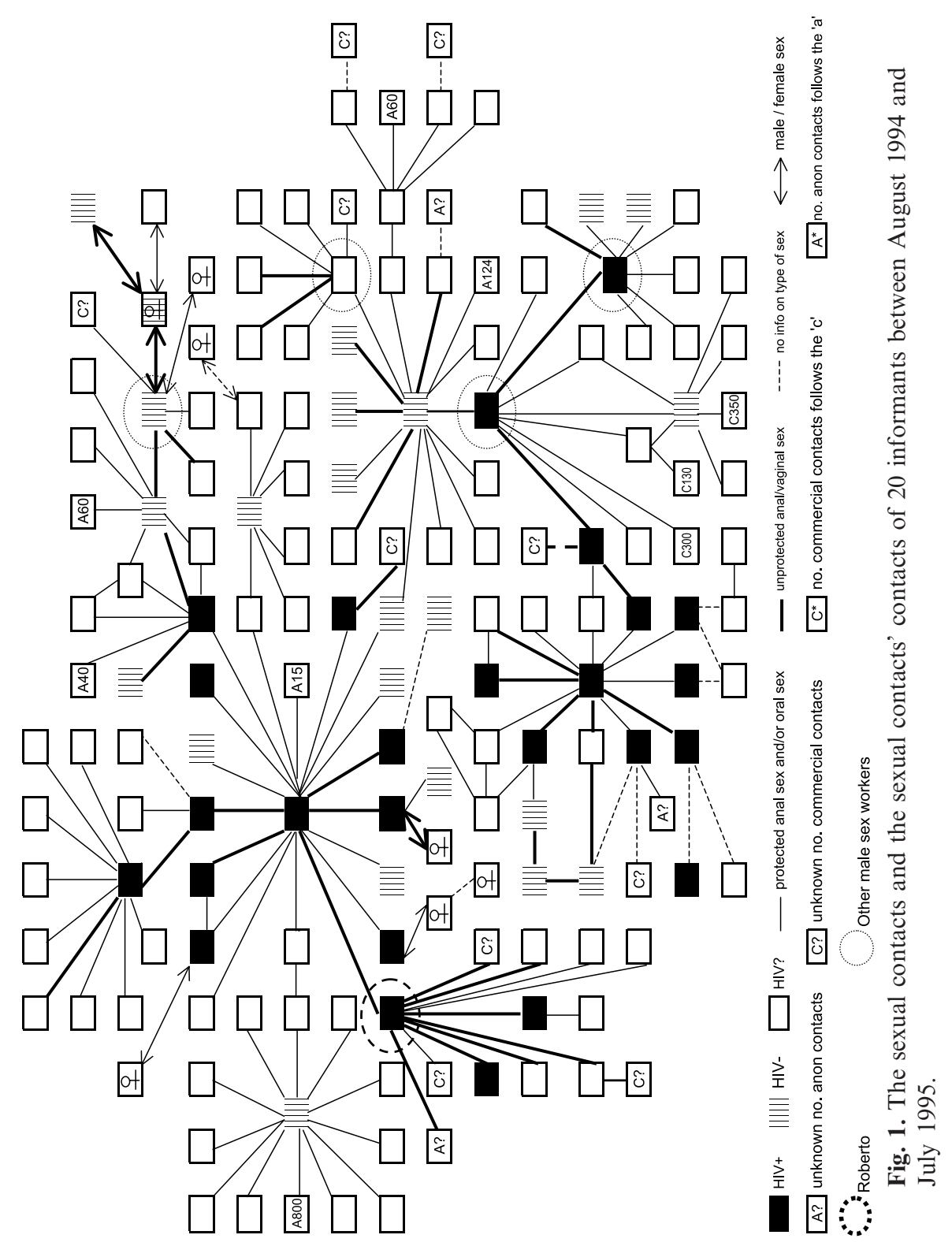




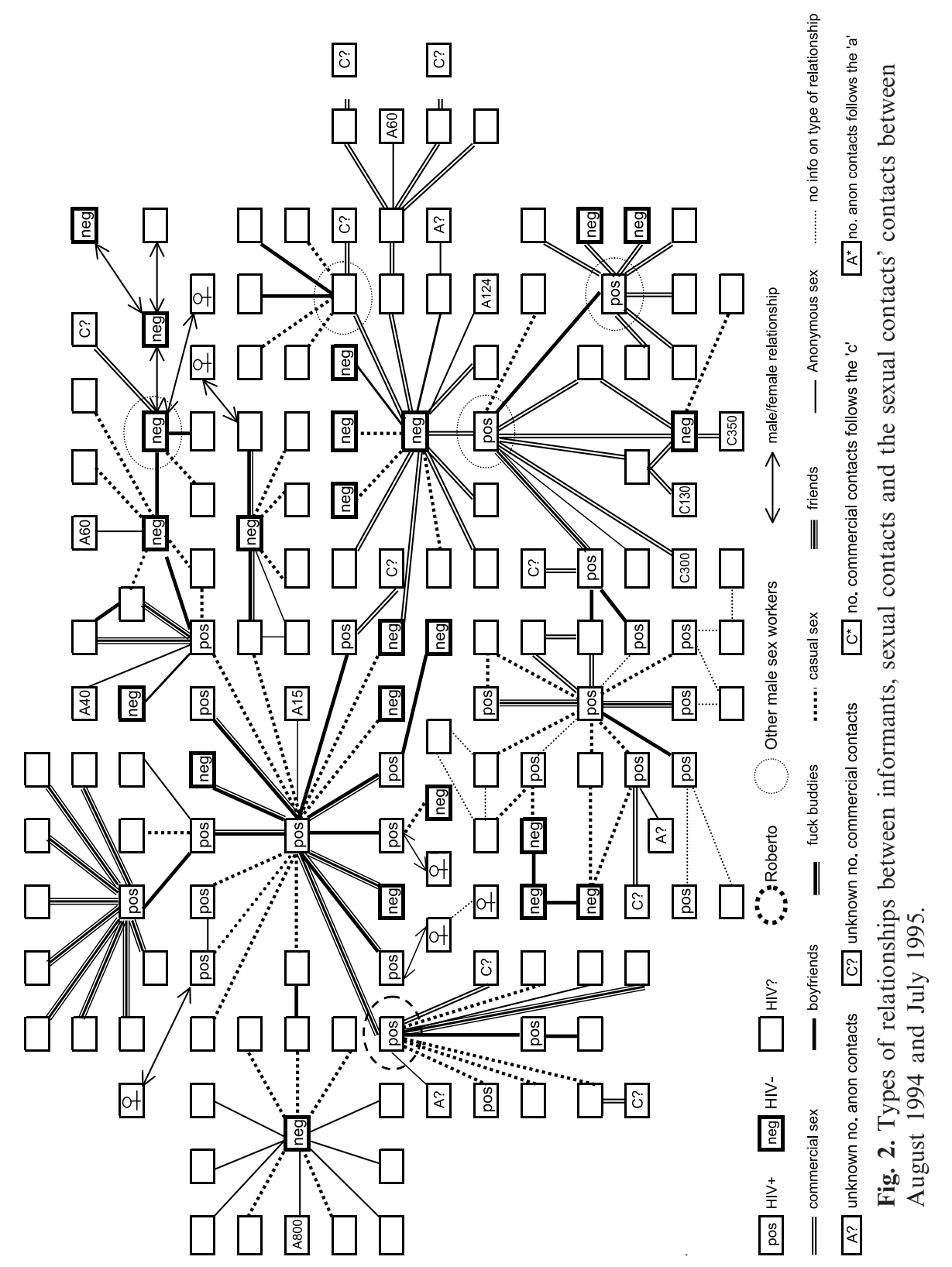


was a friend with whom he had had occasional sexual contact over the previous 12 months and had taken the initiative of mentioning his own HIV status to Roberto prior to having sex with him.

The practice of unprotected anal sex in the knowledge of how HIV is transmitted is difficult to explain in a few lines. From Roberto's point of view, however, a recurring theme was the desire for intimacy, openness and love. Condoms prohibited the possibility of experiencing intimacy and thus he sometimes found himself in situations where he put to one side the knowledge that he may also be transmitting and/or acquiring new HIV infections as this was relatively insignificant compared with his desire to feel wanted and loved.

It is also worth noting that all these sexual relationships were occurring at a difficult time in Roberto's life. A Bolivian transvestite friend had recently died from AIDS in a London teaching hospital; and his own health was deteriorating. $\mathrm{He}$ wanted to go back to South America to live with his mother and sister but he felt he could not return to his country as he did not have the courage to tell them that he was HIV positive and the appropriate drugs to treat his infection were unavailable. This difficult situation became further complicated by the fact that his mother became seriously sick and wished to see him. His family had sent him a ticket so that he could visit her but he could not use it as the Home Office had possession of his passport while they considered his application for permanent residence. Not surprisingly, he found his situation very distressing.

\section{Case studies and sexual network data}

It is helpful to analyse the information emerging from the case study above in the light of ethnographic data detailing social and sexual links between all 20 study informants. Figures 1 and 2 present some of this data. Figure 1 shows that Roberto is part of a complex sexual network comprising 193 men and seven women (as well as a minimum of 1378 untraceable male sexual contacts and 780 commercial contacts). A thick, dotted circular line has been placed around Roberto to highlight his position in the network. Figure 2 depicts the type of sexual contacts that link study informants. For the purposes of this study, six types of contacts are identified in this figure: anonymous sexual contacts; commercial sexual contacts, as well as sexual contacts between boyfriends; casual contacts; 'fuck buddies' and, finally, sexual contacts between men and women. Again, a thick, dotted circular line has been placed around Roberto. A slightly thinner, dotted circular line has been placed around four other male sex workers that form part of this network.

Before analysing the case study about Roberto in the light of these network data, it is important to note that informants such as Roberto refer to sexual relationships in slightly different ways. An anonymous contact, for example, may be variously described as 'a quickie', 'a bit of a rummage' or 'a one-off'. For the purposes of data analysis, however, these terms are grouped together under the broad term 'anonymous sexual contacts' as all these terms refer to sexual contacts that cannot be traced. They have been recruited in public spaces and the sex usually occurs once in a public space such as a park, a public toilet or the darkened backroom of a pub, club or sauna. Conversation is kept to a minimum and so little, if any, social, demographic 
or biomedical information is acquired. By contrast, the term 'commercial sexual contacts' refers to the exchange of sex for money; and this typically occurs through an escort agency, a public place, a 'whore house' or a private advertisement. The term 'boyfriend' refers to a sexual relationship where the informant has or intends to have protracted sexual contact with the person concerned. The men involved in this type of partnership may or may not live with each other and, over time, they acquire an understanding and/or become a part of each other's social worlds. This type of relationship differs from relationships described as 'casual'. Here, sex occurs once or several times but the sexual relationship always fizzles out after a few meetings and the men concerned typically acquire some social, demographic and biomedical information about the person concerned. 'Fuck buddies' are defined as men who have sex with other men over a period of at least six months. The sex is occasional and the men concerned are not part of each other's social worlds and have no intention of becoming a part of each other's social worlds. This type of sexual relationship contrasts with those described by informants as 'friends'. Here, the friendship is longstanding (more than six months) and the sex occasional. It is not a major feature of the relationship.

To return to Roberto: this case study generates a number of themes which resonate with case studies that were developed for the other male sex workers that form part of this network. First, it is not at all clear whether Roberto is more or less likely to have unprotected anal sex with clients than with boyfriends, casual contacts etc. That is, Roberto reported having unprotected sex with three casual contacts, one boyfriend, one 'fuck buddy' and one friend; as well as an unspecified number of commercial and anonymous contacts over a 12 -month period.

A similar picture emerges among the other male sex workers in this network. To be more specific, the other four male sex workers in this network all reported having unprotected sex with boyfriends or girlfriends and, with one exception, contacts that could be loosely classified as 'casual', 'anonymous' and/or 'fuck buddies'. Together, these data suggest that male sex workers are no more or less likely to acquire or transmit HIV in the course of commercial sex compared with other types of sexual relationships. It is, of course, hazardous to generalize from a small number of case studies. However, it is likely that future research will confirm this finding as the one theme that links all male sex workers together is vulnerability and an inability to protect themselves from new infections and/or the possibility of transmitting their infection to others. This, incidentally, contrasts with Ward et al.'s (1993) research on female prostitutes in London. This research suggested that unprotected sex was more likely to take place with boyfriends than with clients.

It is also important to note that men engaging in non-commercial sex all reported having unprotected sex in a variety of contexts (Parker, 1999). In common with male sex workers, there is no single relationship that could be deemed more or less risky than any other relationship. This is not to suggest that the practise of commercial sex carries no risks but rather to draw attention to the point that the type of sexual relationship does not appear to have a great influence on the type of sex practised between men in this network.

This finding raises an important question: do male sex workers in this network constitute a core group? Thomas \& Tucker (1996) highlight the fact that the concept 
of a 'core group' is increasingly used by epidemiologists in different ways, but there is no doubt that there is a tendency for epidemiologists, mathematicians and clinicians to continue to conceptualize sex workers (albeit female sex workers) as core groups. Whatever the merits and limitations of conceptualizing female sex workers as core groups, it is also the case that insights emerging from ethnographic research with male sex workers and their clients, suggest that it would be inappropriate to apply core group theory to male sex workers. Some additional reasons for taking this view include the following: male sex workers in London do not form a distinct social group. Some work on the street, some work in 'whore houses'; some visit their clients at home; and some receive clients in their flats and houses. It is also the case that a large number of male sex workers work in a variety of ways. Roberto, for example, sold sex at a 'whore house' but he also recruited clients through the gay press and visited them at their flats and houses. In addition, social links exist between some male sex workers but the majority of their friends do not sell sex.

Crucially, the majority of men who sell sex in this network do not identify with the terms 'sex workers', 'prostitutes' or the more local terms of 'hooker' and 'whore'. Thus Jonathon, a white, English twenty-two year old, said 'I am a student who sometimes sells sex' and Roberto says 'I am South American and seeking asylum. I shall sell sex until I get permanent residence.' Another male sex worker described himself as a management consultant that 'topped up his income by selling sex' in the evening. The man concerned left school at the age of 16 without any qualifications and moved from Lancashire to London. He was 26 at the time of the interview and owned a luxurious two-bedroom apartment in central London. Further on in this paper, reference is also made to Sam, a white, 40 year old male sex worker from the Home Counties, Southern England. He used to think of himself as a 'normal hooker' but increasingly thinks of himself as a painter and decorator as this is his primary source of income.

From an epidemiological perspective, it is also not clear how, and on what basis, one might say that the male sex workers in this network are any more 'core' than any of the other men in this network. An endeavour was made to illustrate this point by analysing the statistical analysis of the behavioural data collected (such as the total number of sexual contacts; the type of sex undertaken with each contact; and the type of relationship linking each contact). The findings were inconclusive, but no less interesting for that! That is, the number of non-commercial sexual contacts that male sex workers had, over a period of a year, ranged from six to eleven; and the average number of sexual contacts was eight. Some male sex workers felt able to estimate the total number of commercial contacts they had over a period of a year, and if these estimates are included then the average number of contacts increases to 150 a year. The same difficulties arose when analysing the behavioural data for those men that did not sell sex in this network. That is, the number of sexual contacts ranged from three to twenty-nine; and the average number of sexual contacts over a year was seven. These figures exclude my informants' estimates of the number of anonymous contacts they had over a period of a year, but if they are included then the average number of contacts increases to 130 a year. In view of the incomplete nature of these data, there is little to be gained by dwelling on these findings, other than to note their inconclusive nature. 
By contrast, data depicting reported sexual links between male sex workers, their clients and other sexual contacts conveys some useful information. In particular, Figs 1 and 2 show that male sex workers do not play any more of a central role in transmission than many of the other men in this network. For instance, if one removed Roberto and the other male sex workers from the network depicted in Fig 1 , it is still possible to see how HIV can be transmitted through the network. This finding raises an important question: would it be helpful and cost-effective to target male sex workers in London when the category itself makes little sense from a social or epidemiological point of view? The answer is surely 'no!'

It has been suggested elsewhere that it may be helpful to target some of the places where high-risk sex occurs rather than types of people (Parker, 2003). This argument was made with respect to ethnographic research discussing the increasing occurrence of unprotected sex between men in the darkened backrooms of pubs, clubs and saunas in London. With respect to male sex workers, it is hard to see how any single programme can easily target such a diverse group of people, selling sex in diverse contexts, for variable periods of time; with the possible exception of some of the 'whore houses' in London.

Any intervention must, of course, consider the social context in which sex is sold. Here, it is important to note that the sale of sex has become popular and fashionable and this, in part, reflects 'the proud to be gay' subculture in which it has emerged. As one informant said: 'You have really made it if you can find someone who is willing to spend money buying your body.' After all, it is easy to get sex in London. Backrooms in London promote anonymous sex and many men in this network reported having sexual contact with up to 30 men a night. Having a body that is sufficiently desirable for people to spend money on can thus be a real coup.

This is not to deny the fact that selling sex can be fraught and unsettling for some male sex workers. Sam, one of the male sex workers mentioned above, for example, is HIV positive. He was diagnosed with HIV about ten years prior to our first meeting and he clearly felt that his HIV status was beginning to affect his physique. A recurring theme throughout the interviews was the fact that he used to think of himself as a 'normal hooker' but he no longer has the confidence to recruit new clients as he feels that the virus is beginning to affect his body in visible ways. To quote:

\footnotetext{
I feel like I'm out of shape now ... I find it difficult to explain myself [to new clients] on the phone without making myself sound muscular [an illusion to how his body used to be] but then I worry cos I know they're going to come and find something different ... I feel confident [with regular clients] because I know they know me and I assume they like me ... because otherwise they wouldn't come back ... I mean they wouldn't come back just for sex.
}

He went on to say that he had had about ten commercial contacts over the past year and that he had known all these clients for a minimum of five years. The relatively small number of clients meant that he now has to supplement his income by working as a painter and decorator. The distress associated with the move away from selling sex to large numbers of clients is clearly linked to the fact that he no longer feels as if he has a body that is desirable enough to attract a price.

Finally, it is important to reflect upon the quality of data presented in this paper. The case study about Roberto was based upon a series of open-ended, unstructured interviews and numerous social occasions with some of his friends at his flat over a 
period of 12 months. It would not have been possible to have acquired such rich information without a personal recommendation from one of his friends and sexual contacts. Nevertheless, the case material is far from complete. Every interview led my informant to talk more freely about the social, sexual and economic aspects of his life; and there is every reason to suppose that the information presented in Figs 1 and 2 under-estimates, rather than over-estimates, the number and type of sexual relationships. This point also applies to the other informants that contributed to research on sexual networks. That is, all informants were interviewed as much as possible within the time frame of the project. In addition, a great deal of effort was put into socializing and 'hanging out' with informants as this, too, provided a good opportunity to acquire an understanding of their social, sexual and economic worlds. Wherever possible, information about sexual links and HIV status was corroborated with the accounts provided by other informants that were part of this network as well as the clinical records held at the teaching hospital. Without exception, information about HIV status and the links between informants appears to be accurate but it is likely that there has been some under-reporting of the total number of contacts and the occurrence of unprotected anal sex as the time frame of the project meant that it was not possible to talk to informants recruited towards the end of the study more than a couple of times.

\section{Conclusions}

The research presented in this paper has looked, for the first time, at the position of male sex workers in relation to their sexual networks. In so doing, it has been possible to reflect upon the assumptions embedded in the epidemiological concept of a core group and the following important points emerge: first, the category 'male sex worker' is very broad and includes a wide range of men with different social, cultural and economic backgrounds, working in very different contexts. Indeed, it is so diverse that even within the single geographical setting of London, it is far from clear whether it is a useful analytic category. It is certainly not a category that informants in this study identified with.

Second, ethnographic data documenting social and sexual links between male sex workers, their clients and other sexual contacts, suggest that there is a very real possibility of HIV being acquired and/or transmitted during commercial sex. However, there is no evidence to suggest that male sex workers are more or less likely to acquire or transmit HIV in the course of commercial sex compared with other types of sexual relationships. Moreover, men engaging in non-commercial sex all reported having unprotected sex in a variety of contexts and relationships. It thus makes little sense to conceptualize male sex workers as a core group as it is hard to see how they play more of a role in facilitating transmission than many of the other men that are part of their sexual network. This point is borne out by the fact that even if it were possible to remove the male sex workers from the network, it is still possible to see how HIV can be passed from one person to another.

The implications of these findings are wide ranging: there are no short cuts to reducing HIV transmission in London, let alone other parts of Europe and the world. Targeting places such as 'whore houses' by health professionals may well have an 
impact but, almost certainly, the impact will be limited unless these interventions run alongside wider social reforms. In other words, the free availability of treatment and advice for sex workers and their clients may well play a helpful role, but little will be achieved unless a concerted attempt is made to mitigate social and economic vulnerability and to generate a sense of belonging which does not involve the acquisition of HIV. These latter measures apply to all men who have sex with other men and they have little to do with male sex workers per se; a reflection of the fact that there is no evidence to suggest that male sex workers are usefully conceptualized as a core group.

\section{Acknowledgments}

I am grateful to Tim Allen and Azra Ghani for providing helpful comments on an earlier version of this paper.

\section{References}

Anderson, R. M. (1988) The epidemiology of HIV infection: variable incubation plus infectious periods and heterogeneity in sexual activity. Journal of the Royal Statistical Society 151, 66-93.

Anderson, R. M., Gupta, S. \& Ng, W. (1990a) The significance of sexual partner contact networks for the transmission dynamics of HIV. Journal of Acquired Immune Deficiency Syndrome 3, 417-429.

Anderson, R. M., Ng, W., Boily, M. C. \& May, R. M. (1990b) The influence of different sexual contact patterns between age classes on the predicted demographic impact of AIDS in developing countries. Annals of the New York Academy of Sciences 569, 240-274.

Aral, S. O. (2002) Determinants of STD epidemics: implications for phase appropriate intervention strategies. Sexually Transmitted Infections $\mathbf{7 8}$ (supplement 1), i3-i13.

Aral, S. O., St Lawrence, J. S., Tikhonova, I., Safarova, E., Parker, K. A., Shakarishvili, A. \& Ryan, C. (2003) The social organization of commercial sex work in Moscow, Russia. Sexually Transmitted Diseases 30, 39-45.

Boily, M. C., Lowndes, C. \& Alary, M. (2002) The impact of the HIV epidemic phases on the effectiveness of core group interventions: insights from mathematical models. Sexually Transmitted Infections 78 (supplement 1), i78-90.

Communicable Disease Surveillance Centre (2000) HIV and AIDS in the UK: An Epidemiological Review: 2000. Public Health Laboratory Service, London.

Davies, P. \& Feldman, R. (1999) Selling sex in Cardiff and London. In Aggleton, P. (ed.) Men Who Sell Sex: International Perspectives on Male Prostitution and HIVIAIDS. UCL Press, London, pp. 1-22.

D’Costa, L. J., Plummer, F. A., Bowmer, I., Fransen, L., Piot, P., Ronald, A. \& Nsanze, H. (1985) Prostitutes are a major reservoir of sexually transmitted diseases in Nairobi, Kenya. Sexually Transmitted Diseases 12, 64-67.

Fichtenberg, C. M. \& Ellen, J. M. (2003) Moving from core groups to risk spaces. Sexually Transmitted Diseases 30, 825-826.

Hanenberg, R. S., Rojanapithayakorn, W., Kunasol, P. \& Sokal, D. C. (1994) Impact of Thailand's HIV control programme as indicated by the decline of sexually transmitted diseases. Lancet 344, 243-245. 
Health Protection Agency (2005) CDR Weekly 15(41). http://www.hpa.org.uk/cdr/archives/ archive05/hiv_STIs05 htm (accessed October 18th 2005).

Hethcote, H. W. \& Yorke, J. A. (1984) Gonorrhea transmission dynamics and control. Lecture Notes in Biomathematics 156, 23-24.

Kreiss, J. K., Koech, D., Plummer, F. A., Holmes, K. K., Lightfoote, M., Piot, P. et al. (1986) AIDS virus infection in Nairobi prostitutes: extension of the epidemic to East Africa. New England Journal of Medicine 314, 414-418.

McKeganey, N. P. (1994) Prostitution and HIV: what do we know and where might research be targeted in the future? (Editorial) AIDS 8, 1215-1226.

May, M. M. \& Anderson, R. M. (1987) Transmission dynamics of HIV infection. Nature 326, 137-142.

Moses, S., Plummer, F. A. \& Ngugi, E. (1991) Controlling HIV in Africa: effectiveness and cost of an intervention in a high-frequency STD transmitter core group. AIDS 5, 407-411.

Parker, M. (1999) HIV transmission in urban environments: London and beyond. In Schell, L. \& Ulijaszek, S. (eds) Urbanism and Human Biology in Industrialised Countries. Cambridge University Press, Cambridge, pp. 280-308.

Parker, M. (2003) Anthropological reflections on HIV prevention strategies: the case for targeting London's backrooms. In Ellison, G., Parker, M. \& Campbell, C. (eds) Learning from HIV and AIDS. Cambridge University Press, Cambridge, pp. 178-209.

Parker, M., Ward, H. \& Day, S. (1998) Sexual networks and the transmission of HIV in London. Journal of Biosocial Science 30, 60-83.

Plummer, F. A., Nagelkerke, N. J. D., Moses, S., Ndinya-Achola, J. O., Bwayo, J. \& Ngugi, E. (1991) The importance of core groups in the epidemiology and control of HIV-1 infection. AIDS 5 (supplement 1), S169-176.

Sethi, G., Holden, B., Gaffney, J., Greene, L. \& Ward, H. (2004) HIV, sexually transmitted infections and risk behaviours in male sex workers in London over a 10-year period. Paper presented at the British Association for Sexual Health and HIV, Bath 19-21th May 2004. In Sexually Transmitted Infections 80(S1), abstract 239.

Steen, R., Vuylsteke, B., DeCoito, T., Ralepeli, S., Fehler, G., Conley, J. et al. (2000) Evidence of declining STD prevalence in a South African mining community following a core group intervention. Sexually Transmitted Diseases 27(1), 1-8.

Thomas, J. C., Tucker et al. (1996) The development and use of the concept of a sexually transmitted disease core. Journal of Infectious Diseases 174 (supplement 2), S134-143.

Tomlinson, D. R., Hillman, R. J., Harris, J. R. \& Taylor Robinson, D. (1991) Screening for sexually transmitted disease in London-based male prostitutes. Genitourinary Medicine 67, 103-106.

Ward, H., Day, S., Mezzones, J., Dunlop, L., Donegan, C. \& Farrar, S. (1993) Prostitution and risk of HIV: female prostitutes in London. British Medical Journal 307, 356-358.

Ward, H., Day, S. \& Weber, J. (1999) Risky business: health and safety in the sex industry over a 9 year period. Sexually Transmitted Diseases 75, 340-343.

Yorke, J. A., Hethcote, W. H. J. \& Nold, A. (1978) Dynamics and control of the transmission of gonorrhea. Sexually Transmitted Diseases 5, 51-56. 